\title{
Prostatectomy with or without post-operative Radiotherapy: Long-term adverse Effects and Quality of Life
}

\author{
Monsen $\mathrm{KV}^{1,2}$, Fosså SD ${ }^{1}$, Dahl AA ${ }^{1,2}$, Myklebust $\mathrm{T}^{3}$, Smeland $\mathrm{S}^{1}$, Stensvold $\mathrm{A}^{4}$ \\ ${ }^{1}$ National Advisory Unit on Late Effects after Cancer Treatment, Oslo University Hospital, \\ Norway; ${ }^{2}$ Faculty of Medicine, University of Oslo, Norway; ${ }^{3}$ Cancer Registry of Norway, \\ Norway; ${ }^{4}$ Division of Clinical Oncology, Østfold Hospital Trust, Kalnes, Norway
}

\section{Corresponding author:}

Kari Vatne Monsen, MD

National Advisory Unit on Late Effects after Cancer Treatment, Oslo University Hospital Post box 4953 Nydalen, 0424 Oslo, Norway

Phone +4722934000

Email:kava@ous-hf.no

\section{Introduction}

Radical prostatectomy (RP) is a standard treatment for patients with non-metastatic prostate cancer (PCa) [1,2]. After RP, about 15-30\% of the prostatectomized patients develop biochemical recurrence [3,4]. In these patients pelvic salvage radiotherapy is recommended, whereas adjuvant pelvic radiotherapy represents a prophylactic intervention in case of tumor positive resection margins and/or extraprostatic tumor extention in the RP specimen. The life-prolonging effect of post-RP pelvic radiotherapy (RAD) is, however, debated. Any expected favorable survival effect must therefore be balanced against RAD-related adverse 
effects (AEs), which may increase dysfunctions/ problems leading to reduced Health-Related Quality of Life (HRQoL).

According to the literature, patient-reported treatment-related long-term AEs are more frequent and more severe in patients who in addition to RP have undergone post-RP RAD [513]. The impact of post-treatment changes of dysfunctions/problems since the pre-RP situation on HRQoL, assessed by validated patient-completed questionnaires is, however, relatively uncertain, and more research on this field is needed.

In this longitudinal study, we therefore aimed to answer two questions:

1) How much do patient-reported dysfunctions/problems and their development since the preRP situation differ dependent on whether or not post-RP RAD radiotherapy has been applied?

2) What is the difference in long-term post-treatment HRQoL between prostatectomized men who have undergone post-RP RAD and non-irradiated men, and which factors are associated with post-treatment impaired HRQoL?

We expected that, compared to RP alone, post-RP RAD would lead to a greater level of posttreatment dysfunctions/problems and a higher prevalence of men in this group reporting at least one major dysfunction/problem. Further, compared to non-irradiated patients, irradiated men would report larger negative changes (worsening) of existing pre-RP dysfunctions/problems. Worsening is expected to increase the odds of post-treatment impaired HRQoL. 


\section{Material and Methods}

\section{Patients}

The original cohort consisted of 675 patients who in 2008/09 were included into a Norwegian multicenter study which aimed to document AEs related to curative treatment for PCa $[14,15]$. The patients completed a questionnaire immediately before RP (Surveyl), and 541 men of this cohort were in 2016 per mail asked to complete a similar questionnaire (Survey2). The finally evaluable patients fullfilled two criteria: 1) Completion of both Survey1 and Survey2 questionnaire; 2) In case of post-RP RAD: a radiation dose of $\geq 60$ Gy had been applied, and at least four years had passed between start of post-RP RAD and Survey2.

\section{Questionnaires}

The Norwegian version of the EPIC-26 questionnaire represented the main component of the two questionnaires $[16,17]$. This instrument quantifies PCa-related dysfunctions/problems (Symptom Burden) summarized in five Domain Summary Scores (DSSs), each of them transformed into a scale ranging from 0 (worst) to 100 (best). For each DSS, the individual difference between the two Surveys (DSS Change) was calculated by subtracting the DSS at Survey2 from that of Survey1. A DSS Change larger than zero thus reflects worsening of the Symptom Burden. A DSS Change less than zero indicates improvement since the pre-RP situation.

We selected one single item of each EPIC-26 domain to identify men with at least one posttreatment major dysfunction/problem. For the urinary irritative/obstructive, bowel and vitality/hormonal domain, these were patients who reported 'moderate or big problem' related to respectively 'weak urine stream' (item 4d), fecal urgency (item 6a) and 'lack of 
energy' (item 13d). Use of at least one urinary pad per day (item 3) and lack of erection for more than half of the times it was wanted (item 10) were other major dysfunctions/problems.

Both questionnaires also contained the Short Form 12 (SF-12) quality of life questionnaire for evaluation of the HRQoL $[18,19]$. The Physical Component Score (PCS) covers general physical functioning, role-physical, bodily pain and general health. The Mental Component Score (MCS) contains items of vitality, social functioning, role-emotional and mental health. Transformation of the patients' ratings results into a mean normative value of 50 and Standard Deviation (SD) of 10, relevant in Norway's general population [19]. Following Osoba et al. [20], a reduction from the normative value by at least $10 \%$ (PCS/MCS score $\leq 45$ ) was defined as impaired HRQoL.

The questionnaires also contained information on comorbidity (none versus any), paired relationship (yes versus no), educational level (university/college [high] versus less [low]), application of post-RP RAD (no versus yes), and use of androgen deprivation therapy (ADT) (no versus yes). Information on post-RP RAD, date of radiotherapy start and total radiation dose was obtained from the Cancer Registry of Norway.

\section{Statistics}

Mean and SD described continuous variables, whereas frequency and proportion represented categorical variables. Student's t-test- and chi-square tests analyzed inter-group differences. Multivariable logistic regressions (Odds Ratio [OR] with 95\% Confindence Interval [CI]) assessed associations between post-treatment impaired HRQoL (PCS/MCS as dependent variable) and the following independent covariates: DSS Changes, HRQoL scores prior to RP, application of post-RP RAD, and variables with significant inter-group differences in the 
bivariate analyzes. All analyses were performed by SPSS for PC, version 25 and STATA version 5.1. All tests were two-sided, and the significance level was defined as $p<0.05$.

\section{Ethics}

The study was approved by the Regional Ethical Comittee of the South-Eastern Health Region in Norway (no. 2015/429). All participants provided a written informed consent.

\section{Results}

\section{Patients}

The evaluable patients of 380 men, respectively 317 in the RP-only group and 63 in the PR/RAD group, did not differ significantly from the 295 non-evaluable patients (Figure 1, Supplementary Table 1). The median observation time between RP (Survey1) and Survey2 was 7.1 years (range: $6.4-7.8$ ). The median interval between post-RP RAD and Survey2 was 6.0 years (range: $4.2-6.9$ ). A larger proportion of men in the RP-only group had high education compared to men in the RP/RAD group $(p=0.06)$ (Table 1$)$. Among the irradiated men, a higher proportion had high risk tumors, reported post-RP use of ADT and lived without a partner at Survey 2. The median total radiation dose was 70 Gy (range: 62 - 74).

\section{Symptom Burden}

At Survey1, no significant inter-group difference emerged for the DSSs or PCS/MCS scores, justifying the combination of the observed values in both groups (Supplementary Table 2). For each group, Figure 2a displays the development of the DSSs from Survey1 to Survey2, being more often unfavourable for the irradiated than for the non-irradiated men. The largest 
DSS decline since the pre-RP situation was related to the urinary incontinence and sexual domain, with much less decline within the bowel and vitality/hormonal domains. Reduced post-treatment urinary irritative/obstructive problems, particularly in the RP-only group, are visualised by rising DSSs.

In four of the five EPIC-26 domains, with exception of the bowel domain $(p=0.05)$, the posttreatment DSSs were significantly lower in the RP/RAD than in the RP-only group (Table 2a). In the irradiated group, DSS Changes within the urinary incontinence, bowel and vitality/hormonal domain significantly exceeded those observed in the RP-only group. Notably, though based on only four men from the RP/RAD and 13 men from the RP-only group, no significant inter-group difference was observed among the proportion of patients reporting a major problem as to bowel urgency $(p=0.45)$. In sub-analyzes, seperately perfomed in the RP-only and the RP/RAD group, on-going ADT considerably decreased the summary scores of the sexual and vitality/hormonal domains, but not of the bowel and urinary domains (data not shown).

In summary, $90 \%$ of the irradiated men reported at least one post-treatment major dysfunction/problem compared to $80 \%$ in the RP-only group (Table 3). Almost one of three of the irradiated men (29\%) reported three or four of these complaints compared to about one of ten $(11 \%)$ in the RP-only group. On average, about one (1.3) and almost two (1.8) major dysfunctions/problems were described by patients respectively from the RP-only and the RP/RAD group at Survey2.

\section{Health-Related Quality of Life}

Only small inter-group differences emerged for the post-treatment HRQoL scores, though with significantly lower MCS scores among the irradiated men (Table 2b, Figure2b). A higher 
proportion of men in the RP/RAD group, compared to non-irradiated men, reported posttreatment impaired PCS $(p=0.13)$ and impaired MCS $(p=0.27)$.

In the multivariable analyses, rising DSS Changes within three of the five EPIC-26 domains were significantly associated with an increased odds of post-treatment impaired PCS, the sexual $(p=0.05)$ and urinary irritative/obstructive domain being the exceptions (Table 4). Rising DSS Changes within the vitality/hormonal domain were significantly associated with both impaired PCS and impaired MCS. High PCS/MCS scores prior to RP decreased the odds of impaired post-treatment HRQoL. Use of ADT after RP increased the odds of posttreatment HRQoL, more so for PCS (OR: 8.03) than MCS (OR: 1.27). Men living without a partner at Survey 2 had an almost fivefold increased odds for post-treatment impaired MCS. No significant association emerged between the application of post-RP RAD and posttreatment impaired HRQoL.

\section{Discussion}

To the best of our knowledge, this is the first longitudinal study which uses EPIC-26 to report on the unfavourable development of Symptom Burden related to the application of post-RP RAD, thereafter documenting negative, though limited impact of such DSS Changes on posttreatment HRQoL. Our expectation of a greater Symptom Burden in irradiated men are met, with an almost doubled average number of post-treatment major dysfunctions/problems in irradiated than in non-irradiated men. Inspite of worsening within four of the five EPIC-26 domains, the proportion of men with post-treatment more severely impaired HRQoL did not differ significantly between the two comparison groups.

Rising DSS Changes within the urinary incontinence and bowel domain significantly increased the odds of post-treatment impaired PCS. Rising DSS Changes within the 
vitality/hormonal domain was associated with both impaired MCS and impaired PCS. High

HRQoL scores prior to RP protected against the development of post-treatment impaired

HRQoL, whereas use of ADT after RP and living without a partner increased this odds. In this model, post-RP RAD was not associated with post-treatment impaired HRQoL.

\section{Long-term adverse Effects}

In several studies, the prevalence and severity of treatment-induced toxicity has been reported based on physician-based grading systems, not always sufficiently covering the patient's subjective experience of the dysfunctions/problems. We identified only three longitudinal studies which compared patient-reported long-term AEs after RP alone with those after postRP RAD [7-9]. Compared to men with RP alone, van Stam et al. [9] described poorer urinary and poorer erectile function recovery within two years after post-RP RAD without significant inter-group difference for bowel symptoms. Hu et al. [7] used an early version of the EPIC-26 instrument to assess sexual, urinary and bowel function/bother before and after salvage radiotherapy. Irradiated men reported significantly poorer outcomes of sexual function, and of urinary and bowel function/bother. Five years after RP, Moinpur et al. [8] reported more frequent urination in irradiated men, but no significant inter-group differences in bowel movement and erectile dysfunction. The findings of these longitudinal studies are principally supported by two cross-sectional studies $[5,6]$ which documented increased long term AEs in prostatectomized men who had undergone post-RP RAD.

Due to the heterogeneity of study designs and used questionnaires, comparisons between the above studies and our findings are problematic. Nevertheless, our findings support the general view of higher prevalence and more severe AEs in irradiated than in non-irradiated men, though RAD-related deterioration of sexual and bowel dysfunctions/problems seems less in 
our patients than described in the above mentioned literature. Worsening in reported Symptom Burden must also be interpreted on the background of age-related normal changes among men in the general population: After the age of 60 years, urinary, bowel and sexual dysfunctions is not uncommon [21]. In our study the largest declines are observed within the urinary and sexual domain, in line with age-related reduced post-RP recovery in elderly Norwegian men [22]. We confirmed Sanda et al.'s [23] observation of improved urinary irritation/obstruction after RP, this development in our study probably being counteracted by post-RP RAD due to radiation-induced fibrotic tissue changes $[24,25]$.

\section{Post-treatment Quality of Life}

HRQoL was reported in the three above mentioned longitudinal [7-9] and in the two crosssectional studies [5,6]. van Stam et al. [9] did not observe any significant inter-group difference in overall HRQoL. As we, Hu et al. [7] observed significantly poorer PCS after post-RP RAD, but, in contrast to our study, no significant inter-group difference as to posttreatment MCS. Our inter-group difference of MCS may be related to the higher use of postRP ADT in irradiated men, probably initiated due to progressing disease. This higher use has possibly increased the prevalence of post-treatment depression and 'lack of energy' in the RP/RAD group (Supplementary Table 3). In Moinpur et al.'s study [8], irradiated men reported significantly better global HRQoL than non-irradiated men $(p<0.01)$. In that study, and in line with our findings, a high score prior to RP protected against post-treatment reduced global HRQoL. Also in the two cross-sectional studies [5,6], significantly more favourable quality of life was observed in men after RP alone than after post-RP RAD.

The impact of DSS Changes on HRQoL has not formally been studied in any of the above mentioned studies. By using DSS Changes, rather than the prevalence of post-treatment Symptom Burden we took into accont the established principle that the level of treatment- 
related AEs must be interpreted on the background of the pre-treatment situation [26]. Based on the multivariable analyzes of our study, worsening in Symptom Burden within urinary incontinence, bowel, sexual and vitality/hormonal domain, increased the odds of posttreatment impaired HRQoL. Interestingly, worsening within the urinary incontinence and bowel domain impacted negatively significant only on post-treatment PCS, indicating these domains' possible influence on physical functioning, whereas worsening within the vitality/hormonal domain impacted significantly on both post-treatment impaired PCS and MCS. A reasonable explanation is that "lack of energy", the most frequent post-treatment major complaint of the vitality/hormonal domain, negatively impacts both physical and mental health.

On the other hand, the small inter-group differences of the HRQoL scores indicate an overall limited negative impact of treatment-related AEs on quality of life in the majority of patients. Response shift [27] may explain this observation. On the background of a cancer diagnosis, in particular after the experience of recurrence, survivors may accept even high levels of treatment-induced dysfunctions/problems as long as they can maintain a reasonable quality of life.

\section{Clinical relevance}

The lack of significant impact of post-RP RAD on HRQoL in the multivariable regression analyzes is surprising. The most probably explanation is the strong correlation between postRP RAD and DSS Changes. With recent years' increased use of RP in patients with high risk tumors $[1,2,28]$, one has to expect a rising number of men who will be referred to post-RP RAD. Our findings should improve patient councelling before decision of post-RP RAD. The patients should be informed about the increased risk of a greater post-treatment Symptom 
Burden without major decline of the HRQoL. Clinicians should also be aware of that today's increasing use of hormonal treatment prescribed in combination with salvage RAD [29,30] may increase the proportion of patients with impaired HRQoL after post-RP RAD. Future studies have to prove whether new radiation techniques can reduce the number and severity of treatment-related AEs.

\section{Limitations and strengths}

This relatively small-sized study has several limitations. No data are available on radiation field size. The patients are treated by multiple institutions using varying surgical and radiotherapy techniques. This heterogeneity could not be accounted for in this study. Nor could we separate adjuvant from salvage RAD due to lack of PSA level at start of post-RP RAD. Another important limitation is that we did not have information about the individual Symptom Burden immediately before post-RP RAD for improved separation of the effect of RP compared to the true impact of post-PR RAD. In particular we lack sufficient data on use of nerve-sparing surgery.

Quality of life is not only influenced by treatment-related AEs, but is certainly also related to unfavourable social, biological and other health reducing events occurring during the years after RP, most of them unknown to us. There is, however, no reason to anticipate inter-group differences of such conditions in our cohort.

Strengths of this study are its longitudinal design with existing data prior to RP, and for all irradiated patients a follow-up period of more than four years. Another advantage is the use of patient-reported data based on internationally recommended and validated questionnaires thus enabling inter-study comparisons of our findings. 


\section{Conclusion}

Post-prostatectomy pelvic radiotherapy increases long-term adverse effects within the urinary incontinence, bowel, sexual and vitality/hormonal domain assessed by the EPIC-26 instrument, though in most with limited impact on health-related quality of life. On the background of the existing uncertainty about the life-prolonging effect of this additional treatment, it is important that patients, in whom such is planned, are informed about the possibility of these developments. Future studies should show whether improved radiotherapy techniques will result in fewer and less severe adverse effects and thus reduce the possible negative impact on health-related quality of life.

\section{Geolocation information}

This is a nationwide study based on data delivered from patients treated at different hospitals throughout Norway.

\section{Acknowledgements}

We want to thank Siri Lothe Hess and Vigdis Opperud for support during collecting data and for layout tips of this study.

\section{Funding}

This work was financially supported by the Norwegian Cancer Society under Grant no. 5781243; and the Movember Foundation under Grant no. 144974. 


\section{Disclosure of Interest}

The authors report no conflict of interest.

\section{Biographical Note}

Kari Vatne: MD and Ph.D fellow; Sophie D. Fosså: MD (oncologist), Prof.em and senior supervisor; Alv A. Dahl: MD (psychiatrist), Prof. and senior researcher interested in psychooncological issues; Tor Åge Myklebust: MSc, Ph.D, researcher and statistician, Cancer Registry of Norway and Møre/Romsdal Hospital Trust; Sigbjørn Smeland: MD (oncologist), Ph.D, Prof. and Head of Division of Cancer Medicine, Oslo University Hospital and Institute of Clinical Medicine, University of Oslo; and Andreas Stensvold: MD (oncologist), Ph.D, main supervisor and Head of Cancer Department, Østfold Hospital Trust.

\section{References}

1. Mottet N, van den Bergh RCN, Briers E, et al. EAU Guidelines: Prostate Cancer 2019. Eur Association of Urol. 2019. Available from: https://uroweb.org/guideline/prostatecancer/.

2. Solberg A. Nasjonalt handlingsprogram med retningslinjer for diagnostikk, behandling og oppfølging av prostatakreft. 6. utg. ed. Oslo: Helsedirektoratet; 2015.

3. Vatne K, Stensvold A, Myklebust TA, et al. Pre- and post-prostatectomy variables associated with pelvic post-operative radiotherapy in prostate cancer patients: a national registry-based study. Acta Oncol. 2017;56(10):1295-1301.

4. Kneebone A, Bergamin S. Salvage Treatment for Biochemical Failure After Radical Prostatectomy: Do We Now Have the Answers?: Elsevier; 2020. 
5. Adam M, Tennstedt P, Lanwehr D, et al. Functional Outcomes and Quality of Life After Radical Prostatectomy Only Versus a Combination of Prostatectomy with Radiation and Hormonal Therapy. Eur Urol. 2017;71(3):330-336.

6. Adam S, Koch-Gallenkamp L, Bertram H, et al. Health-related quality of life in longterm survivors with localised prostate cancer by therapy-Results from a populationbased study. Eur J of Cancer Care (Engl.). 2019 May 2:e13076.

7. Hu JC, Elkin EP, Krupski TL, et al. The effect of postprostatectomy external beam radiotherapy on quality of life: results from the Cancer of the Prostate Strategic Urologic Research Endeavor. Cancer. 2006;107(2):281-8.

8. Moinpour CM, Hayden KA, Unger JM, et al. Health-related quality of life results in pathologic stage C prostate cancer from a Southwest Oncology Group trial comparing radical prostatectomy alone with radical prostatectomy plus radiation therapy. J Clin Oncol. 2008;26(1):112-20.

9. van Stam MA, Aaronson NK, Pos FJ, et al. The Effect of Salvage Radiotherapy and its Timing on the Health-related Quality of Life of Prostate Cancer Patients. Eur Urol. 2016;70(5):751-757.

10. Suardi N, Gallina A, Lista G, et al. Impact of adjuvant radiation therapy on urinary continence recovery after radical prostatectomy. Eur Urol. 2014;65(3):546-51.

11. Bolla M, van Poppel H, Tombal B, et al. Postoperative radiotherapy after radical prostatectomy for high-risk prostate cancer: long-term results of a randomised controlled trial (EORTC trial 22911). Lancet. 2012;380(9858):2018-27.

12. Thompson IM, Jr., Tangen CM, Paradelo J, et al. Adjuvant radiotherapy for pathologically advanced prostate cancer: a randomized clinical trial. Jama. 2006;296(19):2329-35. 
13. Wiegel T, Bottke D, Steiner U, et al. Phase III postoperative adjuvant radiotherapy after radical prostatectomy compared with radical prostatectomy alone in pT3 prostate cancer with postoperative undetectable prostate-specific antigen: ARO 96-02/AUO AP 09/95. J of Clin Oncol. 2009;27(18):2924-30.

14. Steinsvik EA, Axcrona K, Dahl AA, et al. Can sexual bother after radical prostatectomy be predicted preoperatively? Findings from a prospective national study of the relation between sexual function, activity and bother. BJU Int. 2012;109(9):1366-74.

15. Storas AH, Sanda MG, Boronat OG, et al. Erectile Dysfunction and Sexual Problems Two to Three Years After Prostatectomy Among American, Norwegian, and Spanish Patients. Clin Genitourin Cancer. 2016;14(3):e265-73.

16. Fossa SD, Storas AH, Steinsvik EA, et al. Psychometric testing of the Norwegian version of the Expanded Prostate Cancer Index Composite 26-item version (EPIC-26). Scand J Urol. 2016;50(4):280-5.

17. Martin NE, Massey L, Stowell C, et al. Defining a standard set of patient-centered outcomes for men with localized prostate cancer. Eur Urol. 2015;67(3):460-7.

18. Loyland B, Miaskowski C, Dahl E, et al. Psychological distress and quality of life in long-term social assistance recipients compared to the Norwegian population. Scand J Public Health. 2011;39(3):303-11.

19. Gandek B, Ware JE, Aaronson NK, et al. Cross-validation of item selection and scoring for the SF-12 Health Survey in nine countries: results from the IQOLA Project. International Quality of Life Assessment. J Clin Epidemiol. 1998;51(11):1171-8.

20. Osoba D, Rodrigues G, Myles J, et al. Interpreting the significance of changes in health-related quality-of-life scores. J Clin Oncol. 1998;16(1):139-44. 
21. Donnelly DW, Donnelly C, Kearney T, et al. Urinary, bowel and sexual health in older men from Northern Ireland. BJU Int. 2018;122(5):845-857.

22. Fossa SD, Beyer B, Dahl AA, et al. Improved patient-reported functional outcomes after nerve-sparing radical prostatectomy by using NeuroSAFE technique. Scand J Urol. 2019;53(6):385-391.

23. Sanda MG, Dunn RL, Michalski J, et al. Quality of life and satisfaction with outcome among prostate-cancer survivors. N Engl J Med. 2008;358(12):1250-61.

24. Moltzahn F, Dal Pra A, Furrer M, et al. Urethral strictures after radiation therapy for prostate cancer. Investig Clin Urol. 2016;57(5):309-15.

25. Hofer MD, Gonzalez CM. Management of radiation-induced urethral strictures. Transl Androl Urol. 2015;4(1):66-71.

26. Skolarus TA, Dunn RL, Sanda MG, et al. Minimally important difference for the Expanded Prostate Cancer Index Composite Short Form. Urology. 2015;85(1):101-5.

27. Ring L, Hofer S, Heuston F, et al. Response shift masks the treatment impact on patient reported outcomes (PROs): the example of individual quality of life in edentulous patients. Health Qual of Life Outcomes. 2005;3:55.

28. Delporte G, Henon F, Ploussard G, et al. Radical prostatectomy for locally advanced and high-risk prostate cancer: A systematic review of the literature. Prog Urol. 2018;28(16):875-889.

29. Shipley WU, Seiferheld W, Lukka HR, et al. Radiation with or without Antiandrogen Therapy in Recurrent Prostate Cancer. N Engl J Med. 2017;376(5):417-428.

30. Carrie C, Magne N, Burban-Provost P, et al. Short-term androgen deprivation therapy combined with radiotherapy as salvage treatment after radical prostatectomy for prostate cancer (GETUG-AFU 16): a 112-month follow-up of a phase 3, randomised trial. Lancet Oncol. 2019;20(12):1740-1749. 
Table 1. Medical and sociodemographic Characteristics

\begin{tabular}{|c|c|c|c|}
\hline & $\begin{array}{c}\mathbf{R P}^{1} \text {-only } \\
\mathrm{n}=317\end{array}$ & $\begin{array}{c}\mathbf{R P} / \mathbf{R A D} \mathbf{~}^{2} \\
\mathrm{n}=63\end{array}$ & $p^{3}$ \\
\hline \multicolumn{4}{|l|}{${\text { Survey }{ }^{4}}^{4}$} \\
\hline Age (yrs), mean (SD) & $63(5.4)$ & $63(5.6)$ & 0.39 \\
\hline Clinical risk group, $\mathrm{n}(\%)$ & & & $<0.01$ \\
\hline Low $^{5}$ & $110(35 \%)$ & $12(19 \%)$ & \\
\hline Intermediate $^{6}$ & $152(48 \%)$ & $21(33 \%)$ & \\
\hline High risk ${ }^{7}$ & $55(17 \%)$ & $30(48 \%)$ & \\
\hline Comorbidity, n (\%) & & & 0.74 \\
\hline None & $186(60 \%)$ & $38(62 \%)$ & \\
\hline Any & $124(40 \%)$ & $23(38 \%)$ & \\
\hline Relationship, n (\%) & & & 0.42 \\
\hline Paired & $303(96 \%)$ & $58(94 \%)$ & \\
\hline Unpaired & $13(4 \%)$ & $4(6 \%)$ & \\
\hline Level of education, $n(\%)$ & & & 0.06 \\
\hline $\operatorname{High}^{8}$ & $169(54 \%)$ & $25(40 \%)$ & \\
\hline Low $^{9}$ & $146(46 \%)$ & $37(60 \%)$ & \\
\hline \multicolumn{4}{|l|}{ Survey $^{10}$} \\
\hline Age (yrs), mean (SD) & $70(5.3)$ & $70(5.6)$ & 0.37 \\
\hline Comorbidity, n (\%) & & & 0.39 \\
\hline None & $103(32 \%)$ & $17(27 \%)$ & \\
\hline Any & $214(68 \%)$ & $46(73 \%)$ & \\
\hline Relationship, n (\%) & & & 0.02 \\
\hline Paired & $292(93 \%)$ & $51(84 \%)$ & \\
\hline Unpaired & $23(7 \%)$ & $10(16 \%)$ & \\
\hline \multicolumn{4}{|l|}{ Current ADT ${ }^{11}$ use, n (\%) } \\
\hline No & $287(97 \%)$ & $51(81 \%)$ & 0.02 \\
\hline Yes & $10(3 \%)$ & $6(9 \%)$ & \\
\hline
\end{tabular}

${ }^{1}$ Radical prostatectomy. ${ }^{2}$ Post-operative pelvic radiotherapy. ${ }^{3}$ Significant level: $p<0.05$ (bold). ${ }^{4}$ Year 2008/09 (prior to prostatectomy). ${ }^{5} \mathrm{PSA}<10 \mathrm{ng} / \mathrm{ml}$ and Gleason score $\leq 6$ and clinical tumor category $\leq 2 \mathrm{a}$. ${ }^{6} \mathrm{PSA} 10-20$ $\mathrm{ng} / \mathrm{ml}$ or Gleason score 7 or clinical tumor category $2 \mathrm{~b}$. ${ }^{7}$ Prostate-specific antigen (PSA) $>20 \mathrm{ng} / \mathrm{ml}$ or Gleason score $\geq 8$ or clinical tumor category $\geq 2$ c. ${ }^{8}$ College or university. ${ }^{9}$ High school or lower. ${ }^{10}$ Year $2016 .{ }^{11}$ Androgen deprivation therapy.

The numbers do not always add up to $\mathrm{N}=380$ (RP-only: $\mathrm{n}=317$; RP/RAD: $\mathrm{n}=63$ ) due to missing data. 
Table 2.

a) EPIC-26: Domain Summary Scores, Changes, and number of Patients (\#) with major Dysfunctions/Problems of one selected single Item per Domain

\begin{tabular}{|c|c|c|c|c|}
\hline & Survey $1^{1}$ & \multicolumn{3}{|c|}{ Survey $2^{2}$} \\
\hline & $\begin{array}{c}\text { All } \\
\text { patients }\end{array}$ & $\begin{array}{c}\mathbf{R P}^{3} \text {-only } \\
\mathrm{n}=317\end{array}$ & $\begin{array}{c}\mathbf{R P} / \mathbf{R A D} \mathbf{D}^{4} \\
\mathrm{n}=63\end{array}$ & $p^{5}$ \\
\hline Urinary Incontinence, mean (SD) & $94(12.2)$ & $74(27.3)$ & $61(31.6)$ & $<0.01$ \\
\hline Change $^{6}$, mean $(\mathrm{SD})$ & & $+20(26.8)$ & $+33(32.2)$ & $<0.01$ \\
\hline$\#^{7}$ Use of $\geq$ one pad per day (item 3$), \mathrm{n}(\%)$ & $6(2 \%)$ & $107(34 \%)$ & $32(52 \%)$ & 0.01 \\
\hline Urinary Irritative/Obstructive, mean (SD) & $83(14.9)$ & $91(11.8)$ & $84(14.2)$ & $<0.01$ \\
\hline Change $^{6}$, mean $(\mathrm{SD})$ & & $-7(15.3)$ & $-2(21.9)$ & 0.14 \\
\hline$\#^{7}$ Weak urine stream (item $\left.4 d\right), \mathrm{n}(\%)$ & $55(15 \%)$ & $20(7 \%)$ & $8(13 \%)$ & 0.07 \\
\hline Bowel, mean (SD) & $95(9.9)$ & $93(14.1)$ & $89(13.1)$ & 0.05 \\
\hline Change $^{6}$, mean $(\mathrm{SD})$ & & $+2(13.6)$ & $+7(12.8)$ & 0.02 \\
\hline$\#^{7}$ Urgency (item 6a), n (\%) & $3(1 \%)$ & $13(4 \%)$ & $4(6 \%)$ & 0.45 \\
\hline Sexual, mean (SD) & $68(24.0)$ & $29(26.5)$ & $18(17.2)$ & $<0.01$ \\
\hline Change $^{6}$, mean $(\mathrm{SD})$ & & $+39(29.8)$ & $+45(25.1)$ & 0.16 \\
\hline$\#^{7}$ Erectile dysfunction (item 10$), \mathrm{n}(\%)$ & $62(17 \%)$ & $227(73 \%)$ & $55(90 \%)$ & $<0.01$ \\
\hline Vitality/Hormonal, mean (SD) & $92(11.5)$ & $89(15.6)$ & $79(20.2)$ & $<0.01$ \\
\hline Change $^{6}$, mean $(\mathrm{SD})$ & & $+2(14.0)$ & $+12(20.7)$ & $<0.01$ \\
\hline$\#^{7}$ Lack of energy (item 13d), n (\%) & $28(7 \%)$ & $38(12 \%)$ & $15(24 \%)$ & 0.02 \\
\hline
\end{tabular}

${ }^{1}$ Year 2008/09 (prior to prostatectomy). ${ }^{2}$ Year 2016. ${ }^{3}$ Radical prostatectomy. ${ }^{4}$ Post-operative pelvic radiotherapy. ${ }^{5}$ Significant level: $p<0.05$ (bold). ${ }^{6}$ Domain summary score difference between Survey1 and Survey2: worsening (+); improvement (-). ${ }^{7}$ For definition cfr. Methods.

b) SF-12: Health-Related Quality of Life reflected by Physical and Mental Component Summary Scores

\begin{tabular}{|c|c|c|c|c|}
\hline & Survey1 $^{1}$ & \multicolumn{3}{|c|}{ Survey2 $^{2}$} \\
\hline & $\begin{array}{c}\text { All } \\
\text { patients }\end{array}$ & $\begin{array}{c}\text { RP }^{3} \text {-only } \\
\mathrm{n}=317\end{array}$ & $\begin{array}{c}\text { RP/RAD }^{4} \\
\mathrm{n}=63\end{array}$ & $\boldsymbol{p}^{5}$ \\
\hline $\begin{array}{l}\text { Physical Component Summary (PCS), mean (SD) } \\
\text { Impaired (PCS score } \leq 45), \mathrm{n}(\%)\end{array}$ & $52(6.4)$ & $48(9.8)$ & $46(9.7)$ & 0.08 \\
& $43(12 \%)$ & $78(28 \%)$ & $21(38 \%)$ & 0.13 \\
$\begin{array}{l}\text { Mental Component Summary (MCS), mean (SD) } \\
\text { Impaired (MCS score } \leq 45), \mathrm{n}(\%)\end{array}$ & $53(8.6)$ & $54(8.0)$ & $51(9.3)$ & $\mathbf{0 . 0 2}$ \\
& $61(17 \%)$ & $44(15 \%)$ & $12(21 \%)$ & 0.27 \\
\hline
\end{tabular}

${ }^{1}$ Year 2008/09 (prior to prostatectomy). ${ }^{2}$ Year 2016. ${ }^{3}$ Radical prostatectomy. ${ }^{4}$ Post-operative pelvic radiotherapy.

${ }^{5}$ Significant level: $p<0.05$ (bold). 
Table 3. Number of Patients (\#) with long-term post-treatment major Dysfunctions/Problems as to the five selected EPIC-26 single Items

\begin{tabular}{|l|c|c|c|}
\hline \multicolumn{1}{|c|}{ Major Dysfunctions/Problems ${ }^{2}$} & \multicolumn{2}{|c|}{ Survey2 $^{1}$} \\
\hline Reported number & $\begin{array}{c}\mathbf{R P}^{3} \text {-only } \\
\mathrm{n}=317\end{array}$ & $\begin{array}{c}\mathbf{R P}^{2} \mathbf{R A D}^{4} \\
\mathrm{n}=63\end{array}$ & $\boldsymbol{p}^{5}$ \\
None & $63(20 \%)$ & $6(9 \%)$ & $<\mathbf{0 . 0 1}$ \\
One & $145(46 \%)$ & $21(33 \%)$ \\
Two & $75(24 \%)$ & $18(29 \%)$ \\
Three & $26(8 \%)$ & $15(24 \%)$ \\
Four & $8(2 \%)$ & $3(5 \%)$ \\
Five & None & None & \\
Total number & & 114 & \\
Average per patient & 405 & 1.8 & \\
\hline
\end{tabular}

${ }^{1}$ Year 2016. ${ }^{2}$ For definition and item selection cfr. Methods. ${ }^{3}$ Radical prostatectomy. ${ }^{4}$ Post-operative pelvic radiotherapy. ${ }^{5}$ Significant level: $p<0.05$ (bold). 
Table 4. Multivariable regression Analyzes with Prevalence of impaired Physical (a) and Mental (b) Quality of Life being the outcome Variables

\begin{tabular}{|c|c|c|c|}
\hline \multirow[t]{2}{*}{ a) } & \multicolumn{3}{|c|}{$\begin{array}{l}\text { Impaired Physical Component Summary } \\
\text { (PCS) score at Survey } 2^{1}\end{array}$} \\
\hline & $\mathbf{O R}^{2}$ & $p^{3}$ & $95 \% \mathrm{CI}^{4}$ \\
\hline $\begin{array}{l}\text { Post-RP }^{5} \text { pelvic Radiotherapy } \\
\text { No } \\
\text { Yes }\end{array}$ & $\begin{array}{l}\text { ref. } \\
0.85\end{array}$ & 0.73 & $0.35-2.08$ \\
\hline $\begin{array}{l}\text { ADT }^{6} \text { use after } \mathbf{R P}^{5} \\
\text { No } \\
\text { Yes }\end{array}$ & $\begin{array}{l}\text { ref. } \\
8.03\end{array}$ & 0.01 & $1.66-38.82$ \\
\hline PCS prior to $\mathbf{R P}^{5}$ & 0.88 & $<0.01$ & $0.83-0.93$ \\
\hline Age at $\mathbf{R P}^{5}$ & 1.03 & 0.34 & $0.97-1.10$ \\
\hline $\begin{array}{l}\text { High risk Group }^{7} \\
\text { Yes } \\
\text { No }\end{array}$ & $\begin{array}{l}\text { ref. } \\
0.98\end{array}$ & 0.96 & $0.43-2.23$ \\
\hline $\begin{array}{l}\text { Level of Education } \\
\text { High }^{8} \\
\text { Low }^{9}\end{array}$ & $\begin{array}{l}\text { ref. } \\
1.29\end{array}$ & 0.45 & $0.66-2.51$ \\
\hline $\begin{array}{l}{\text { Paired Relationship at Survey } 2^{1}} \\
\text { Yes } \\
\text { No }\end{array}$ & $\begin{array}{l}\text { ref. } \\
2.36\end{array}$ & 0.11 & $0.82-6.80$ \\
\hline $\begin{array}{l}\text { Change of EPIC-26 Domain Summary Score } \\
\text { Urinary Incontinence } \\
\text { Urinary Irritative/Obstructive } \\
\text { Bowel } \\
\text { Sexual } \\
\text { Vitality/Hormonal } \\
\end{array}$ & $\begin{array}{l}1.01 \\
.99 \\
1.03 \\
1.01 \\
1.03 \\
\end{array}$ & $\begin{array}{l}\mathbf{0 . 0 3} \\
0.59 \\
\mathbf{0 . 0 1} \\
0.05 \\
\mathbf{0 . 0 2}\end{array}$ & $\begin{array}{l}1.00-1.03 \\
0.97-1.02 \\
1.00-1.05 \\
1.00-1.02 \\
1.00-1.05\end{array}$ \\
\hline
\end{tabular}

\begin{tabular}{|c|c|c|c|}
\hline \multirow[t]{2}{*}{ b) } & \multicolumn{3}{|c|}{$\begin{array}{l}\text { Impaired Mental Component Summary } \\
\text { (MCS) score at Survey } 2^{1}\end{array}$} \\
\hline & $\mathbf{O R}^{2}$ & $p^{3}$ & $95 \% \mathrm{CI}^{4}$ \\
\hline $\begin{array}{l}\text { Post-RP }^{5} \text { pelvic Radiotherapy } \\
\text { No } \\
\text { Yes }\end{array}$ & $\begin{array}{l}\text { ref. } \\
1.62\end{array}$ & 0.36 & $0.57-4.57$ \\
\hline $\begin{array}{l}\text { ADT }^{6} \text { use after } \mathbf{R P}^{5} \\
\text { No } \\
\text { Yes }\end{array}$ & $\begin{array}{l}\text { ref. } \\
1.27\end{array}$ & 0.77 & $0.25-6.41$ \\
\hline MCS prior to $\mathbf{R P}^{5}$ & 0.90 & $<0.01$ & $0.86-.94$ \\
\hline Age at RP $\mathbf{P}^{5}$ & 0.99 & 0.93 & $0.92-1.07$ \\
\hline $\begin{array}{l}\text { High risk Group }^{7} \\
\text { Yes } \\
\text { No }\end{array}$ & $\begin{array}{l}\text { ref. } \\
1.95\end{array}$ & 0.27 & $0.60-6.33$ \\
\hline $\begin{array}{l}\text { Level of Education } \\
\text { High }^{8} \\
\text { Low }^{9}\end{array}$ & $\begin{array}{l}\text { ref. } \\
1.11\end{array}$ & 0.81 & $0.48-2.54$ \\
\hline $\begin{array}{l}\text { Paired Relationship at Survey2 }^{1} \\
\text { Yes } \\
\text { No }\end{array}$ & $\begin{array}{l}\text { ref. } \\
4.90\end{array}$ & $<0.01$ & $1.48-16.27$ \\
\hline $\begin{array}{l}\text { Change of EPIC-26 Domain Summary Score } \\
\text { Urinary Incontinence } \\
\text { Urinary Irritative/Obstructive } \\
\text { Bowel } \\
\text { Sexual } \\
\text { Vitality/Hormonal } \\
\end{array}$ & $\begin{array}{l}1.01 \\
1.00 \\
1.01 \\
1.01 \\
1.04 \\
\end{array}$ & $\begin{array}{r}0.25 \\
0.96 \\
0.60 \\
0.23 \\
<\mathbf{0 . 0 1} \\
\end{array}$ & $\begin{array}{l}0.99-1.02 \\
0.97-1.03 \\
0.98-1.03 \\
0.99-1.02 \\
1.02-1.07\end{array}$ \\
\hline
\end{tabular}

${ }^{1}$ Year 2016. ${ }^{2}$ Odds ratio. ${ }^{3}$ Significant level: $p<0.05$ (bold). ${ }^{4}$ Confidence interval. ${ }^{5}$ Radical prostatectomy.

${ }^{6}$ Androgen deprivation therapy. ${ }^{7}$ Prostate-specific antigen $>20 \mathrm{ng} / \mathrm{ml}$ or Gleason score $\geq 8$ or clinical tumor category $\geq 2$ c. ${ }^{8}$ College or university. ${ }^{9}$ High school or lower. 
